\title{
Carbono mineralizável, carbono orgânico e nitrogênio em macroagregados de Latossolo sob diferentes sistemas de uso do solo no Cerrado Goiano
}

\author{
Mineralizable carbon, organic carbon and nitrogen in \\ macroaggregates of an Oxisol under different systems \\ soil usages in Cerrado Goiano
}

\author{
Arcângelo Loss ${ }^{1 *}$; Marcos Gervasio Pereira²; Sidinei Julio Beutler³; \\ Adriano Perin ${ }^{4}$; Lúcia Helena Cunha dos Anjos ${ }^{2}$
}

\section{Resumo}

\begin{abstract}
A integração lavoura-pecuária (ILP) em sistema plantio direto (SPD) pode aumentar o teor de carbono mineralizável, carbono orgânico e nitrogênio dos macroagregados do solo quando comparada a áreas de SPD, sem pastejo. O objetivo deste trabalho foi quantificar o carbono mineralizável e os teores de carbono orgânico total (COT) e nitrogênio $(\mathrm{N})$ de macroagregados de Latossolo sob diferentes sistemas de uso do solo no Cerrado Goiano. Foram avaliadas duas áreas com rotação de culturas: ILP (milho+braquiária/ feijão/algodão/soja) e SPD (girassol/milheto/soja/milho). Uma área de Cerrado natural foi tomada como condição original do solo. Foram coletadas amostras indeformadas nas camadas de 0-5 e 5-10 cm, sendo posteriormente incubadas em laboratório em delineamento inteiramente casualizado. Avaliou-se a quantidade de $\mathrm{C}-\mathrm{CO}_{2}$ desprendida de cada amostra de agregados diariamente (até 37 dias) e, também, a respiração total de $\mathrm{C}-\mathrm{CO}_{2}$ acumulada. Antes e após a incubação foram quantificados os teores de COT, $\mathrm{N}$ e a relação $\mathrm{C} / \mathrm{N}$. A área de ILP apresentou maiores valores de $\mathrm{C}-\mathrm{CO}_{2}(0-5 \mathrm{~cm}) \operatorname{logo}$ após a incubação quando comparada às demais áreas. Aos 7 dias após a incubação, nos três sistemas avaliados, observou-se um aumento na liberação de $\mathrm{C}-\mathrm{CO}_{2}$ e, a partir do $25^{\circ}$ dia ocorreu a estabilização da respiração microbiana. Entre as áreas cultivadas, a área de ILP apresentou maior acúmulo de $\mathrm{C}-\mathrm{CO}_{2}$ e maiores teores de COT, $\mathrm{N}$ (antes e depois da incubação) e, menor relação C/N, antes da incubação. A ILP promoveu maiores acúmulos de $\mathrm{C}-\mathrm{CO}_{2}$ quando comparada a área de SPD. A integração dos fatores rotação de culturas, plantas de cobertura (braquiária) e pastejo bovino no sistema de ILP aumentam o carbono mineralizável (acúmulos de $\mathrm{C}-\mathrm{CO}_{2}$ ), COT e $\mathrm{N}$ nos macroagregados em comparação a área de SPD.
\end{abstract}

Palavras-chave: Integração lavoura-pecuária, sistema plantio direto, milho/braquiária, atividade microbiana, carbono lábil

\section{Abstract}

The crop-livestock integration system (CLIS) associated to a no-tillage system (NTS) may increase mineralizable carbon, organic carbon and nitrogen of soil macroaggregates when compared with only

1 Prof. Adjunto, Dept $^{\circ}$ de Engenharia Rural, Centro de Ciências Agrárias, Universidade Federal de Santa Catarina, UFSC, Florianópolis, SC. E-mail: arcangeloloss@yahoo.com.br

2 Profs. Associados IV, Dept ${ }^{\circ}$ de Solos, Instituto de Agronomia, Universidade Federal Rural do Rio de Janeiro, UFRRJ, Seropédica, RJ. E-mail: gervasio@ufrrj.br; lanjos@ufrrj.br

3 Discente de Doutorado do CPGA-CS, Dept ${ }^{\circ}$ Solos, UFRRJ, Seropédica, RJ. E-mail: s.paraná@yahoo.com.br

4 Prof. do Instituto Federal de Educação, Ciência e Tecnologia, Campus Rio Verde, Rod. Sul Goiana, km 01, Zona Rural, Rio Verde, GO, 75901-970. E-mail: perinrj@yahoo.com.br

Autor para correspondência 
NTS area, without grazing. The aim of this study was to quantify mineralizable carbon, total organic carbon (TOC) and nitrogen of macroaggregates in different land management systems in Cerrado region, Goias State. There were evaluated two areas with crop rotation: CLIS (Brachiaria+corn/bean/ cotton/soybean) and NTS (sunflower/millet/soy/corn). A Cerrado area with natural vegetation was taken as reference for the original soil. Undisturbed soil samples were taken at $0-5$ and $5-10 \mathrm{~cm}$ depth, and then incubated in laboratory, with the samples set in a randomized design. There were evaluated the $\mathrm{C}-\mathrm{CO} 2$ detached daily (up to 37 days) from each sample and total respiration of $\mathrm{C}-\mathrm{CO}_{2}$ accumulated were also analyzed. Before and after incubation of soil aggregates ( 0 to 5 and 5 to $10 \mathrm{~cm}$ ), the TOC, $\mathrm{N}$ and $\mathrm{C} / \mathrm{N}$ were quantified. The CLIS samples showed higher $\mathrm{C}-\mathrm{CO}_{2}(0-5 \mathrm{~cm})$ immediately after incubation when compared to other samples. At 7 days after incubation, in the three systems, there was an increase of $\mathrm{C}-\mathrm{CO}_{2}$ liberation and, after the 25th day the microbial respiration was stabilized. Comparing the cultivated areas, CLIS showed higher $\mathrm{C}-\mathrm{CO}_{2}$ accumulation and the highest TOC, N (before and after incubation), and lower $\mathrm{C} / \mathrm{N}$ ratio, before incubation. The CLIS increased higher $\mathrm{C}-\mathrm{CO}_{2}$ accumulations than the NTS area. The integration of the factors crop rotation, cover crops (brachiaria) and cattle grazing in the CLIS increase mineralizable carbon (C- $\mathrm{CO}_{2}$ accumulations), TOC and $\mathrm{N}$ in macroaggregates compared to the NTS area.

Key words: Crop-livestock integration system, no-tillage system, corn/brachiaria, microbial activity, labile carbon

\section{Introdução}

Há aproximadamente 200 anos, o homem vem interferindo massivamente no fluxo global de carbono (C), sendo a agricultura convencional, embasada no uso de arados e grades, a grande responsável pelas perdas de carbono do solo (MACHADO, 2005). Sistemas de preparo convencional com revolvimento do solo por aração e gradagem apresentam decréscimo expressivo nos estoques de matéria orgânica do solo (MOS) em comparação ao sistema plantio direto (SPD) (LEITE et al., 2010; TEIXEIRA; LA SCALA JÚNIOR; LOPES, 2010; LOSS et al., 2010; BODDEY et al., 2010) e aos sistemas de integração lavoura-pecuária (ILP) (TRACY; ZHANG, 2008; MACEDO, 2009; ANGHINONI et al., 2011; LIEBIG et al., 2012). Portanto, sistemas de produção que resultam no aumento dos teores da MOS, a exemplo do SPD e ILP, têm sido apontados como mais sustentáveis, devido a relação direta e indireta da MOS com a melhoria dos atributos edáficos (MIELNICZUK et al., 2003; FONTANA et al., 2006; VILELA et al., 2011; LOSS et al., 2011, 2012a).

O sistema de ILP, implantado através do SPD, é um sistema de manejo da produção agrícola que contribui para o aumento do sequestro de carbono e dos estoques de nutrientes no solo (LOSS et al., 2012a,b), além de favorecer a manutenção da agregação do solo e aumento dos teores de MOS (SILVA et al., 2011; LOSS et al., 2011). Esses benefícios são potencializados pela introdução de espécies forrageiras, pois de forma geral, as forrageiras acumulam mais carbono em comparação às culturas agrícolas, cuja fitomasssa se mostra, muitas vezes, insuficiente para a manutenção da cobertura do solo (CARVALHO, 2007; EMBRAPA, 2009; SOUZA et al., 2009; LOSS et al., 2011). A introdução de culturas agrícolas associadas a pastagens em SPD, com destaque para a braquiária, pode resultar em melhores condições ambientais, uma vez que a diversidade observada neste sistema, os caminhos do fluxo de nutrientes e outros processos comuns na natureza resultam em uma agricultura mais conservacionista (CARVALHO et al., 2010; FERREIRA et al., 2011; ANGHINONI et al., 2011).

Avaliando os estoques de carbono orgânico total (COT) e estoques de carbono da matéria orgânica particulada em Latossolo Vermelho de textura argilosa no Cerrado (GO) em áreas cultivadas com soja sobre braquiária e soja sobre sorgo, ambas em SPD, Rossi et al. (2012) encontraram maiores valores dessas frações da MOS na área com a braquiária. Os autores concluíram que os resultados encontrados são decorrentes do maior aporte de palhada da braquiária e também da contribuição do 
sistema radicular via rizodeposição para aumentar os teores de MOS. Em outro estudo sobre os estoque de COT em áreas com ILP, SPD e vegetação natural de Cerrado (Cerradão) sob Latossolo Vermelho, GO, Loss et al. (2012a) verificaram que os estoques de COT foram maiores na área de ILP (130,95 $\left.\mathrm{Mg} \mathrm{ha}^{-1}\right)$ quando comparados com a área de Cerradão (125,34 $\left.\mathrm{Mg} \mathrm{ha}^{-1}\right)$ e SPD (116 Mg ha-1) para a camada de 0-60 cm. E, os autores atribuíram essas diferenças ao efeito da integração de plantas de cobertura (braquiária) consorciada ao milho safrinha no sistema de ILP, propiciando a deposição de resíduos culturais de degradação mais lenta e, portanto, favorecendo o acúmulo de COT pela sua maior relação $\mathrm{C} / \mathrm{N}$.

Várias culturas têm sido utilizadas nos sistemas de ILP, entre as quais se destacam: soja, milho, milheto, sorgo, nabo forrageiro, girassol, algodão e gramíneas forrageiras tropicais, principalmente as braquiárias (Urochloa $\mathrm{sp}$ ), consorciadas ou não. Entretanto, poucos experimentos de longa duração com o uso de rotação lavoura-pecuária em ecossistemas tropicais e subtropicais, com ênfase nas modificações ocasionadas na agregação do solo, têm sido relatados (CARVALHO, 2007, 2009; FRANCHINI et al., 2010; LOSS et al., 2011). Dessa forma, tornam-se necessários mais estudos sobre o sistema de ILP, principalmente em relação à emissão de $\mathrm{C}-\mathrm{CO}_{2}$ (carbono mineralizável) dos macroagregados do solo.

A taxa de decomposição do material orgânico e a conseqüente liberação de $\mathrm{C}-\mathrm{CO}_{2}$ são determinadas principalmente pelas características intrínsecas da própria matéria orgânica, tais como: relação $\mathrm{C} / \mathrm{N}$; teores de carboidrato, lignina; grau de agregação; características do solo $(\mathrm{pH}$, teores de nutrientes e umidade) e características do ambiente (temperatura e precipitação) (DAVIDSON; BELK; BOONE, 1998; BROOKES, 1995). A atividade microbiana de um solo inclui todas as reações metabólicas celulares, suas interações e seus processos bioquímicos mediados ou conduzidos pelos organismos do solo. A liberação de gás carbônico ou respiração edáfica está diretamente relacionada à decomposição da matéria orgânica e a mineralização do húmus (SIQUEIRA et al., 1994).

Quando se adiciona ao solo fonte de carbono, estimula-se a respiração microbiana. Este padrão é observado pela adição de carboidrato simples, por exemplo, glicose, que é uma molécula pequena e com ligações simples, facilmente decomponível e que pode ser submetida a uma rápida metabolização pela população microbiana do solo, consequentemente induz a liberação de $\mathrm{C}-\mathrm{CO}_{2}$ para a atmosfera (FARIAS et al., 2005).

A atividade microbiana tem papel de destaque no cenário da sustentabilidade ambiental (SOUZA et al., 2010) e pode ser estimada por métodos relativamente simples. Dentre estes, destaca-se o C mineralizável que é quantificado a partir da evolução de $\mathrm{CO}_{2}$ (ZIBILSKE, 1994) oriundo da respiração de microrganismos heterotróficos aeróbicos durante a oxidação de compostos orgânicos (KENNEDY; SMITH, 1995; BOSSUYT; SIX; HENDRIX, 2002; ASSIS JÚNIOR; KAZUYA; COUTO, 2003).

A partir do exposto, este trabalho teve como objetivo quantificar o carbono mineralizável e os teores de carbono orgânico total e nitrogênio total de macroagregados de um Latossolo sob diferentes sistemas de uso do solo no Cerrado Goiano.

\section{Material e Métodos}

O estudo foi realizado na Fazenda Vargem Grande, pertencente à Agropecuária Peeters, localizada em Montividiu, GO (17 $\left.21^{\circ} \mathrm{S} ; 51^{\circ} 28^{\prime} \mathrm{W}\right)$. $\mathrm{O}$ clima da região se caracteriza por duas estações bem definidas: uma seca (de maio a setembro) e outra chuvosa (outubro a abril) (Figura 1). 
Figura 1. Valores médios de precipitação pluviométrica e temperatura no ano de 2008. Fonte: Estação Meteorológica da Fesurv - Universidade de Rio Verde ( $17^{\circ} 48^{\prime} \mathrm{S}$; 50 55’W, Rio Verde, GO).

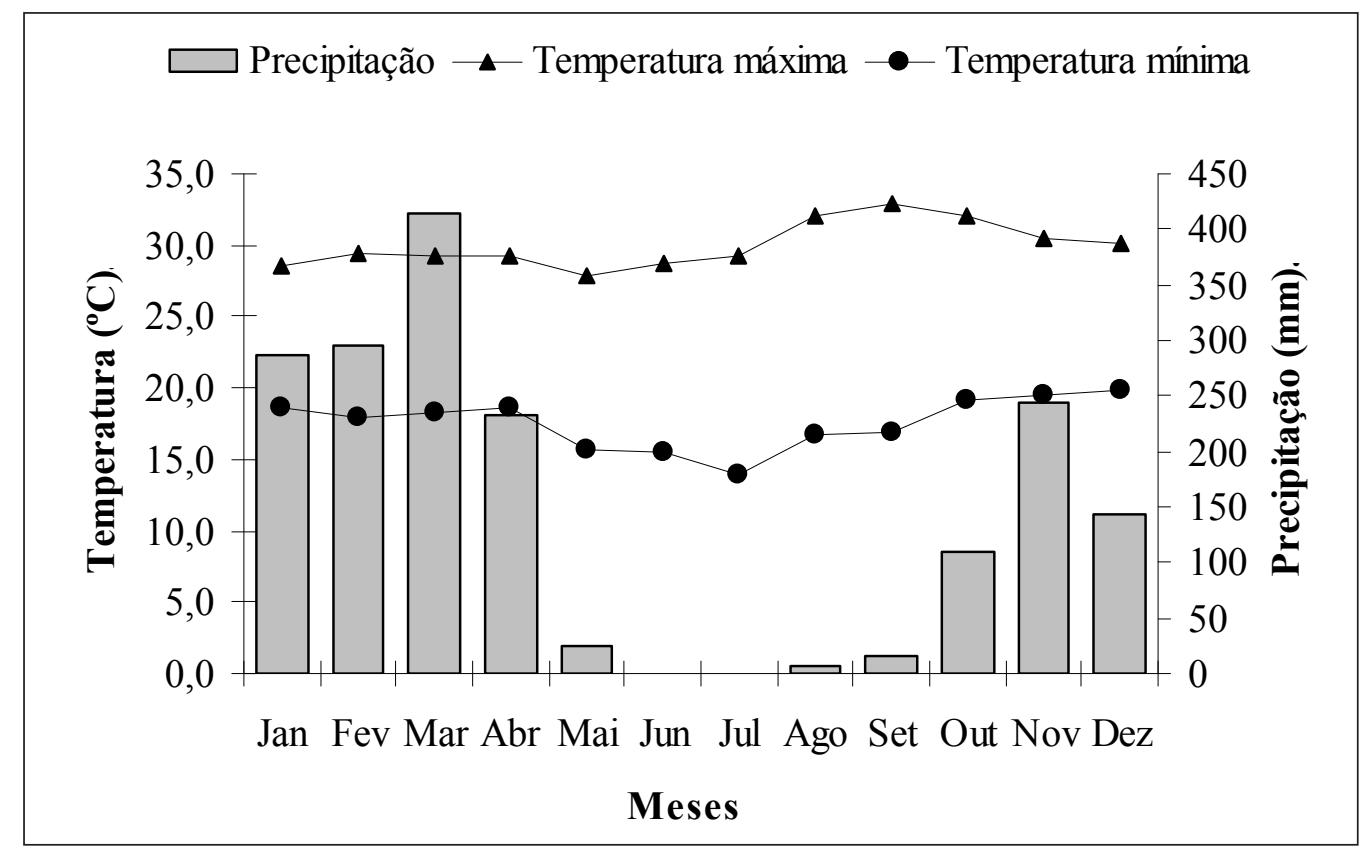

Fonte: Elaboração dos autores.

O solo nas áreas foi classificado como Latossolo Vermelho Distrófico com textura muito argilosa (EMBRAPA, 2006). Na composição mineralógica da fração argila predominam a gibbsita, caulinita e a hematita (SIQUEIRA NETO, 2006; LOSS, 2011).

A cobertura vegetal original da área é o Cerrado, com fitofisionomia do tipo Cerradão (vegetação de caráter florestal). A vegetal original foi retirada em 1975 para implantação de pastagens (Urochloa decumbens). Em seguida, a área foi preparada por meio de aração e gradagem niveladora (sistema de preparo convencional - SPC) para posterior semeadura da $U$. decumbens. Esta permaneceu na área por 10 anos, sob uso contínuo, até 1985 (Figura 2).

Figura 2. Histórico dos usos e processos de mudança do uso da terra, com as respectivas datas de implantação, na Fazenda Vargem Grande da Agropecuária Peeters, em Montividiu, GO.

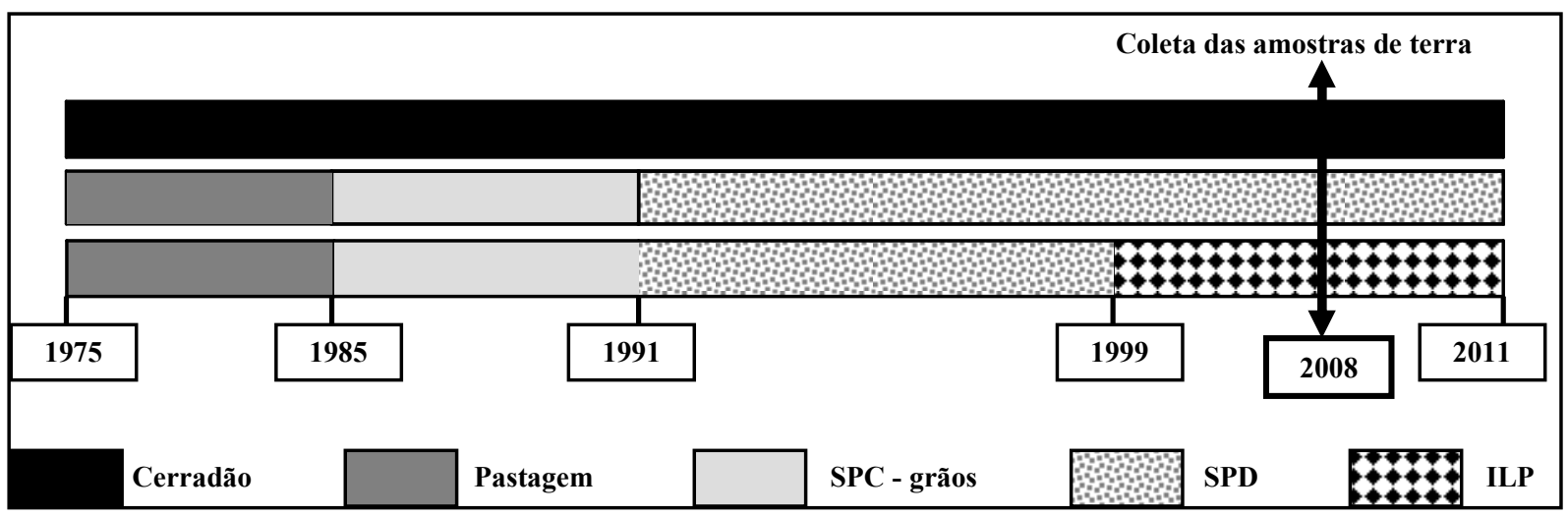

Fonte: Elaboração dos autores. 
A partir de 1985, as áreas foram cultivadas com grãos (milho, feijão, soja e girassol) sob SPC (aração e gradagem niveladora) até o ano de 1991. Posteriormente, foi implantado o Sistema de Plantio Direto (SPD) com rotação de culturas (milho, soja, algodão, feijão) e, a partir de 1999, parte do SPD foi transformado em Integração Lavoura-Pecuária (ILP). Portanto, as áreas avaliadas vêm sendo conduzidas em SPD com as mesmas rotações de culturas, sendo SPD somente (1991 a 2008) e ILP (1999 a 2008) (Figura 2).

Os sistemas avaliados consistiram de duas áreas cultivadas em SPD por 17 anos (1991 a 2008): uma somente com rotação de culturas (SPD: girassolmilheto-soja-milho), e outra com braquiária ( $U$. ruziziensis) em consórcio ao milho safrinha, para intensificar a produção de palhada no período seco do ano (ILP: milho-braquiária-feijão-algodão-soja). No sistema de ILP (9 anos: 1999 a 2008), o milho e a braquiária foram semeados simultaneamente (braquiária na entrelinha e o milho na linha). Após a colheita do milho, foi feita a introdução de bovinos na área (2,0 UA por ha, sendo UA - unidade animal), com permanência dos animais por 90 dias (julho a setembro). Após a retirada do gado, permaneceram apenas as touceiras de braquiária na área. Quando da ocasião das primeiras chuvas, realizou-se uma adubação em cobertura na braquiária com $200 \mathrm{~kg} \mathrm{ha}^{-1}$ do formulado N P K (20:00:20) a lanço na primeira quinzena de setembro. Após a rebrota, quando a área estava totalmente coberta pela capineira, foi feita a dessecação e o plantio do feijão. Uma área de Cerrado (Cerradão) natural mais próxima às áreas cultivadas e sob o mesmo solo (17²6.642'S; $51^{\circ} 22.522^{\prime} \mathrm{W}$ e altitude $951 \mathrm{~m}$ ) foi considerada como condição original do solo.

Nas áreas sob ILP e SPD, aplicaram-se, em 2005, 3,60 e 2,90 Mg ha ${ }^{-1}$ de calcário dolomítico, com PRTN $=70 \%$, para a elevação da saturação por bases para $70 \%$ e $60 \%$, respectivamente. A sequência de culturas e adubações utilizadas nas duas áreas, desde o ano de 2002 até 2008, é apresentada na Tabela 1. $\mathrm{Na}$ área de SPD, todo mês de agosto, foi realizada a semeadura do milheto para produção de palhada para o plantio da soja em outubro. Anteriormente a 2002, a área permanecia em pousio durante os meses de maio a setembro, nascendo na área plantas da família das gramíneas, como o colonião e a braquiária. Na área de ILP, a utilização da cultura do milho e a braquiária semeados simultaneamente (braquiária na entrelinha) ocorreu em um total de 5 vezes (Tabela 1 ).

Tabela 1. Sequência de culturas e adubações utilizadas nas áreas avaliadas da Fazenda Vargem Grande da Agropecuária Peeters, em Montividiu, GO.

\begin{tabular}{|c|c|c|c|c|c|c|c|c|}
\hline \multirow{3}{*}{ Ano } & \multirow{2}{*}{ Mês } & \multirow{2}{*}{ Cultura } & \multicolumn{6}{|c|}{$\mathrm{Kg} \mathrm{ha}^{-1}$ de $\mathrm{N}-\mathrm{P}_{2} \mathrm{O}_{5}-\mathrm{K}_{2} \mathrm{O}$} \\
\hline & & & \multicolumn{3}{|c|}{ Plantio } & \multicolumn{3}{|c|}{ Cobertura } \\
\hline & \multicolumn{8}{|c|}{ Área de ILP (milho-braquiária-feijão-algodão-soja) } \\
\hline 2002 & Outubro & Soja & 12 & 116 & 105 & & $\begin{array}{l}------- \\
\end{array}$ & \\
\hline 2003 & Fevereiro & Milho+Braquiária & 35 & 140 & 70 & 45 & 0,0 & 0,0 \\
\hline 2003 & Outubro & Soja & 12 & 116 & 105 & & ------- & \\
\hline 2004 & Fevereiro & Milho+Braquiária & 32 & 126 & 63 & 45 & 0,0 & 0,0 \\
\hline 2004 & Outubro & Soja & 10 & 100 & 90 & & --------- & \\
\hline 2005 & Fevereiro & Milho + Braquiária & 34 & 137 & 69 & 45 & 0,0 & 0,0 \\
\hline 2005 & Setembro & Feijão & 20 & 80 & 40 & 41 & 0,0 & 0,0 \\
\hline 2005 & Dezembro & Algodão & 50 & 150 & 50 & 50 & 0,0 & 50 \\
\hline 2006 & Outubro & Soja & 10 & 100 & 90 & & -------- & \\
\hline
\end{tabular}


continuação

\begin{tabular}{|c|c|c|c|c|c|c|c|c|}
\hline 2007 & Fevereiro & Milho+Braquiária & 32 & 126 & 63 & 45 & 0,0 & 0,0 \\
\hline 2007 & Outubro & Soja & 9 & 90 & 81 & & -------- & \\
\hline 2008 & Fevereiro & Milho+Braquiária & 32 & 126 & 63 & 45 & 0,0 & 0,0 \\
\hline 2008 & Setembro & Feijão & 20 & 80 & 40 & 41 & 0,0 & 0,0 \\
\hline \multirow[t]{2}{*}{2008} & Dezembro & Algodão & 50 & 150 & 50 & 50 & 0,0 & 50 \\
\hline & \multicolumn{8}{|c|}{ Área de SPD (girassol-milheto-soja-milho) } \\
\hline 2002 & Agosto & Milheto & & 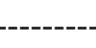 & & & ---------- & \\
\hline 2002 & Outubro & Soja & 12 & 116 & 105 & & --------- & \\
\hline 2003 & Fevereiro & Milho & 32 & 126 & 63 & 45 & 0,0 & 0,0 \\
\hline 2003 & Agosto & Milheto & & ------- & & & --------- & \\
\hline 2003 & Outubro & Soja & 12 & 116 & 105 & & -------- & \\
\hline 2004 & Fevereiro & Milho & 32 & 126 & 63 & 45 & 0,0 & 0,0 \\
\hline 2004 & Agosto & Milheto & & ------ & & & --------- & \\
\hline 2004 & Outubro & Soja & 12 & 116 & 105 & & --------- & \\
\hline 2005 & Fevereiro & Milho & 32 & 126 & 63 & 45 & 0,0 & 0,0 \\
\hline 2005 & Agosto & Milheto & & & & & --------- & \\
\hline 2005 & Outubro & Soja & 12 & 116 & 105 & & --------- & \\
\hline 2006 & Fevereiro & Girassol & 6 & 60 & 60 & 45 & 0,0 & 0,0 \\
\hline 2006 & Agosto & Milheto & & -------- & & & --------- & \\
\hline 2006 & Outubro & Soja & 10 & 100 & 90 & & --------- & \\
\hline 2007 & Fevereiro & Milho & 28 & 112 & 56 & 45 & 0,0 & 0,0 \\
\hline 2007 & Agosto & Milheto & & ------- & & & --------- & \\
\hline 2007 & Outubro & Soja & 10 & 100 & 90 & & --------- & \\
\hline 2008 & Fevereiro & Girassol & 6 & 60 & 60 & 45 & 0,0 & 0,0 \\
\hline 2008 & Agosto & Milheto & & ------- & & & --------- & \\
\hline 2008 & Outubro & Soja & 10 & 100 & 90 & & --------- & \\
\hline
\end{tabular}

Fonte: Elaboração dos autores.

As áreas encontravam-se cultivadas com girassol em SPD e milho + braquiária em ILP quando da coleta das amostras de solo para avaliação (Figura 2). Para a coleta das amostras foi delimitada uma área de $\pm 600 \mathrm{~m}^{2}$, sendo abertas quatro minitrincheiras transversais às linhas de semeadura em cada área. Para a coleta dos agregados foram retirados blocos indeformados (EMBRAPA, 1997) nas camadas de 0-5 e 5-10 cm, com auxílio de espátula, nas trincheiras descritas acima, sendo cuidadosamente acondicionados em sacos plásticos e identificados. Os agregados do solo, coletados na faixa de friabilidade, foram manualmente separados até toda a amostra passar em um conjunto de peneiras de 8 e 4 mm (EMBRAPA, 1997), secos a sombra e armazenados para as análises de evolução do $\mathrm{C}-\mathrm{CO}_{2}$ em laboratório.

As amostras dos agregados, secas ao ar, foram reumedecidas (GONÇALVES et al., 2002) por pulverização com água, duas vezes ao dia (manhã e noite) durante duas semanas. Em seguida foi determinada a capacidade de campo segundo o método do funil. Para tal, pesaram-se $30 \mathrm{~g}$ de agregados, colocando-as num funil de plástico com $10 \mathrm{~cm}$ de diâmetro, vedado com lã de vidro na base, para evitar perda de material. Posteriormente, os agregados foram saturados com água deionizada. Os funis foram cobertos com filme plástico para minimizar perdas de água por evaporação e assim 
permaneceram por 4-6 horas para drenagem do excesso de água. Em seguida, cerca de $5 \mathrm{~g}$ de cada amostra de agregados foram secas em estufa a $105^{\circ} \mathrm{C}$ até atingir massa constante. A capacidade de campo foi determinada utilizando a seguinte equação: $\mathrm{CC}=\mathrm{P} 1-\mathrm{P} 2$ / P2; onde, $\mathrm{CC}$. = capacidade de campo; $\mathrm{P} 1=$ massa da amostra de solo úmida $(\mathrm{g})$; $\mathrm{P} 2=$ massa da amostra de solo seca $(\mathrm{g})$.

Para a avaliação do $\mathrm{C}-\mathrm{CO}_{2}$ em laboratório, utilizou-se o método proposto por Mendonça e Matos (2005). Foram pesados $50 \mathrm{~g}$ de agregados que passaram pela peneira de $8,00 \mathrm{~mm}$ e ficaram acondicionados na peneira de 4,00 $\mathrm{mm}$ (após reumedecidos) e colocados em recipientes de vidro de $500 \mathrm{~cm}^{3}$, com fechamento hermético, sendo a umidade dos agregados do solo ajustada para 65 $\%$ da capacidade de campo. A cada recipiente foi adicionado um frasco contendo $30 \mathrm{~mL}$ de solução de $\mathrm{NaOH} 0,5 \mathrm{~mol} \mathrm{~L}^{-1}$, para capturar o C-CO $\mathrm{CO}_{2}$ e outro contendo $30 \mathrm{~mL}$ de $\mathrm{H}_{2} \mathrm{O}$ (para manter a umidade constante). Os recipientes de vidro (4 repetições por sistema de uso do solo) foram dispostos em delineamento inteiramente casualizado, sendo a temperatura ambiente (dentro do laboratório) mantida em $25{ }^{\circ} \mathrm{C}$ por meio de refrigeração.

As amostragens e posteriormente os cálculos de $\mathrm{C}-\mathrm{CO}_{2}$ foram feitos em intervalos de $24 \mathrm{~h}$ nos primeiros 7 dias, de $48 \mathrm{~h}$ entre o $8^{\circ}$ e o $17^{\circ}$ dia e de $96 \mathrm{~h}$ entre o $18^{\circ}$ e $37^{\circ}$ dia. Antes e após a incubação dos agregados do solo $(0-5$ e $5-10 \mathrm{~cm})$ foi quantificado o carbono orgânico total (COT) segundo Yeomans e Bremmer (1988) e o nitrogênio total $(\mathrm{N})$ conforme Tedesco, Volkweiss e Bohnen (1995), sendo calculada a relação C/N.

Os resultados foram analisados quanto à normalidade e homogeneidade dos dados por meio dos testes de Lilliefors e Cochran e Barttlet, respectivamente. Posteriormente, foi analisado como delineamento inteiramente casualizado (DIC), com três sistemas de uso do solo - tratamentos (SPD, ILP e Cerradão) com 4 repetições cada. Os sistemas de uso do solo avaliados estão sob as mesmas condições topográficas e edafoclimáticas, diferindo apenas no sistema de uso da terra (LOSS, 2011). Os resultados foram submetidos à análise de variância, aplicando o teste $\mathrm{F}$ e os valores médios, se significativos, comparados entre si pelo teste LSD-student a $5 \%$. Para a evolução diária de $\mathrm{C}-\mathrm{CO}_{2}$ realizou-se análise de variância, com aplicação do teste $\mathrm{F}$ e teste LSD-student a 5\%, para cada dia de avaliação (fator tempo) e para cada profundidade (0-5 e 5-10 cm) separadamente.

\section{Resultados e Discussão}

A área de ILP apresentou maiores valores de C- $\mathrm{CO}_{2}(0-5$ e 5-10 cm) logo após a incubação quando comparada às demais áreas (Figura 3). A maior liberação de $\mathrm{C}-\mathrm{CO}_{2}$ pela área de ILP pode ser devido à maior disponibilidade de $\mathrm{C} \mathrm{e} \mathrm{N}$ presente na fração leve livre (FLL) da matéria orgânica do solo (MOS) (LOSS et al., 2012b) e carbono facilmente oxidável (LOSS, 2011), associados a menor relação $\mathrm{C} / \mathrm{N}$ entre as áreas avaliadas antes da incubação (Tabela 2). Somados a essas informações, ainda tem-se a presença de duas leguminosas (soja e feijão - Tabela 1), mais o uso da braquiária e dos dejetos bovinos deixados em superfície na rotação da ILP. Dessa forma, no sistema de ILP, o conjunto de fatores rotação de culturas, plantas de cobertura e pastejo dos animais compõem um sistema integrado de produção, que propicia maiores picos de $\mathrm{C}-\mathrm{CO}_{2}$ quando comparado com as demais áreas. No sistema de ILP, o uso da braquiária por meio da produção de palhada e de sua capacidade de exploração do solo por meio do sistema radicular, apresenta grande absorção e acúmulo de nutrientes (CRUSCIOL; BORGHI, 2007), sendo os mesmos liberados para o solo a partir da decomposição de sua palhada e rizodepozição. Este padrão acarreta em maior atividade microbiana resultando em aceleração da decomposição da MOS, com incorporação parcial do $\mathrm{C}$ presente em estruturas orgânicas dos microorganismos, sendo a maior parte liberada na forma de $\mathrm{C}-\mathrm{CO}_{2}$ (BALDOCK et al., 1992). As áreas de Cerradão e de SPD apresentaram padrão semelhante logo após a incubação ( $1^{\circ}$ dia $)$ (Figura 3). 
Figura 3. Evolução diária de $\mathrm{C}-\mathrm{CO}_{2}$ nas amostras de agregados ( $\mathrm{A}$ =profundidade de $0-5 \mathrm{~cm}$ e $\left.\mathrm{B}=5-10 \mathrm{~cm}\right)$ incubados até os 37 dias de avaliação, nos diferentes sistemas de uso do solo em Montividiu, Goiás.*= significativo pelo teste t-LSD a 5\%; ns=não significativo pelo teste $\mathrm{F}$ a 5\%. SPD = sistema plantio direto (girassol-milheto-soja-milho); ILP = integração lavoura-pecuária (milho-braquiária-feijão-algodão-soja).

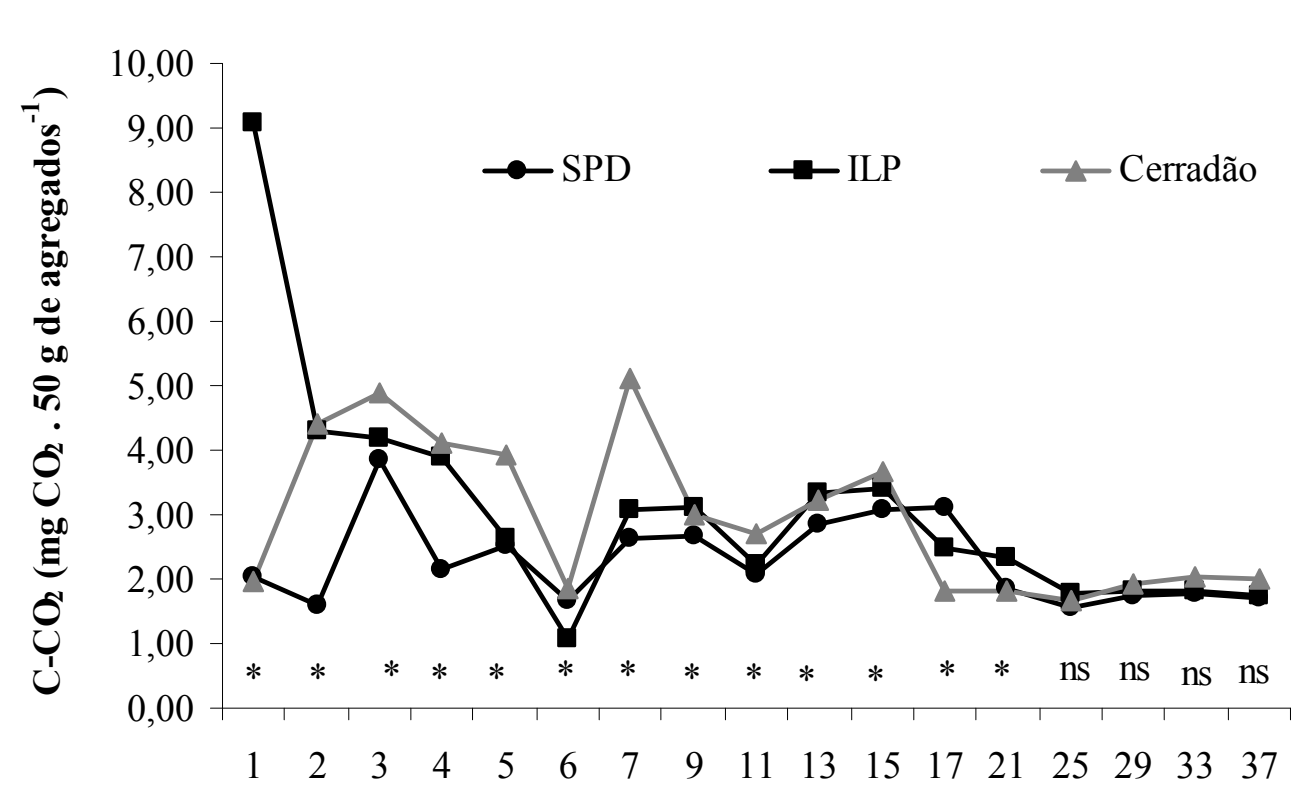

Dias após a incubação

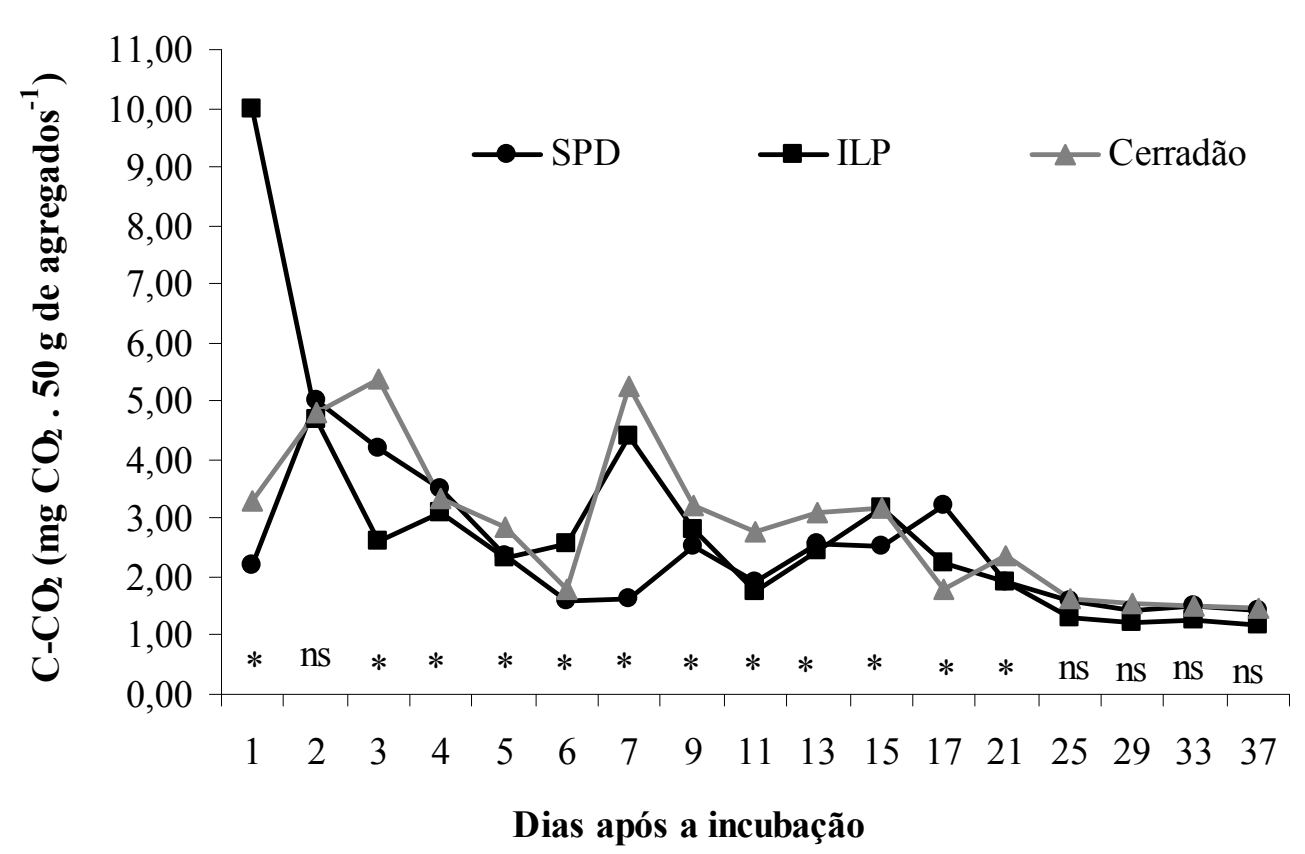

Fonte: Elaboração dos autores. 
Tabela 2. Carbono orgânico total (COT, $\left.\mathrm{g} \mathrm{kg}^{-1}\right)$, nitrogênio total ( $\left.\mathrm{N}, \mathrm{g} \mathrm{kg}^{-1}\right)$ e relação C/N antes e após a incubação dos agregados do solo nos diferentes sistemas de uso do solo em Montividiu, GO.

\begin{tabular}{|c|c|c|c|c|}
\hline \multirow{3}{*}{ Agregados do solo } & \multicolumn{4}{|c|}{ Sistemas de uso do solo } \\
\hline & SPD & ILP & Cerradão & $\mathrm{CV}(\%)$ \\
\hline & \multicolumn{4}{|c|}{ COT $(0,0-0-5,0 \mathrm{~cm})$} \\
\hline Antes da incubação & $22,24 \mathrm{aC}$ & $24,57 \mathrm{aB}$ & $40,71 \mathrm{aA}$ & 5,45 \\
\hline Após a incubação & $23,25 \mathrm{aC}$ & $25,53 \mathrm{aB}$ & $35,29 \mathrm{bA}$ & 6,25 \\
\hline \multirow[t]{2}{*}{$\mathrm{CV}(\%)$} & 9,21 & 10,25 & 6,81 & \\
\hline & \multicolumn{4}{|c|}{$\operatorname{COT}(5,0-10,0 \mathrm{~cm})$} \\
\hline Antes da incubação & $21,66 \mathrm{aB}$ & $21,42 \mathrm{aB}$ & $28,11 \mathrm{aA}$ & 6,21 \\
\hline Após a incubação & $21,43 \mathrm{aB}$ & $19,56 \mathrm{aB}$ & $25,38 \mathrm{bA}$ & 7,33 \\
\hline \multirow[t]{2}{*}{$\mathrm{CV}(\%)$} & 11,23 & 12,35 & 6,99 & \\
\hline & \multicolumn{4}{|c|}{$\mathrm{N}(0,0-0-5,0 \mathrm{~cm})$} \\
\hline Antes da incubação & $2,84 \mathrm{aB}$ & $4,41 \mathrm{aA}$ & $4,32 \mathrm{bA}$ & 7,26 \\
\hline Após a incubação & $3,36 \mathrm{aB}$ & $3,80 \mathrm{bB}$ & $5,59 \mathrm{aA}$ & 7,89 \\
\hline \multirow[t]{2}{*}{$\mathrm{CV}(\%)$} & 8,26 & 6,31 & 5,25 & \\
\hline & \multicolumn{4}{|c|}{$\mathrm{N}(5,0-10,0 \mathrm{~cm})$} \\
\hline Antes da incubação & $2,23 \mathrm{aB}$ & $2,71 \mathrm{aA}$ & $2,96 \mathrm{bA}$ & 8,23 \\
\hline Após a incubação & $2,27 \mathrm{aC}$ & $2,70 \mathrm{aB}$ & $3,87 \mathrm{aA}$ & 6,25 \\
\hline \multirow[t]{2}{*}{$\mathrm{CV}(\%)$} & 8,88 & 9,52 & 4,23 & \\
\hline & \multicolumn{4}{|c|}{$\mathrm{C} / \mathrm{N}(0,0-0-5,0 \mathrm{~cm})$} \\
\hline Antes da incubação & $7,83 \mathrm{aB}$ & $5,57 \mathrm{aC}$ & $9,42 \mathrm{aA}$ & 4,23 \\
\hline Após a incubação & $6,92 \mathrm{aA}$ & $6,72 \mathrm{aA}$ & $6,31 \mathrm{bB}$ & 5,61 \\
\hline \multirow[t]{2}{*}{$\mathrm{CV}(\%)$} & 8,55 & 9,23 & 8,21 & \\
\hline & \multicolumn{4}{|c|}{$\mathrm{C} / \mathrm{N}(5,0-10,0 \mathrm{~cm})$} \\
\hline Antes da incubação & $9,71 \mathrm{aA}$ & $7,90 \mathrm{aB}$ & $9,50 \mathrm{aA}$ & 6,32 \\
\hline Após a incubação & $9,44 \mathrm{aA}$ & $7,24 \mathrm{aB}$ & $6,56 \mathrm{bC}$ & 5,22 \\
\hline $\mathrm{CV}(\%)$ & 9,57 & 8,59 & 7,25 & \\
\hline
\end{tabular}

Médias seguidas de mesma letra maiúscula na linha não diferem entre os sistemas avaliados, para cada período de incubação, pelo teste t-LSD a 5\% e, mesma letra minúscula na coluna não difere entre o período de incubação, para cada sistema avaliado, pelo teste t-LSD a 5\%. CV=coeficiente de variação. SPD = sistema plantio direto (girassol-milheto-soja-milho); ILP = integração lavourapecuária (milho-braquiária-feijão-algodão-soja).

Fonte: Elaboração dos autores.

Com a maior disponibilidade de MOS para a microbiota do solo verificou-se que a área de ILP apresentou evolução de $\mathrm{C}-\mathrm{CO}_{2}$ cerca de sete vezes superior ao das outras áreas (Figura 3, $1^{\circ}$ dia) (LOSS, 2011; LOSS et al., 2011; 2012b). Este padrão já foi relatado na literatura e é conhecido como efeito "priming", em que a estimulação da atividade microbiana pela adição de resíduos orgânicos e/ ou maior disponibilidade de MOS prontamente decomponível (menor relação $\mathrm{C} / \mathrm{N}$ ) favorece a aceleração da decomposição daMOS(KUZYAKOV;
FRIDEL; STAHR, 2000), aumentando a evolução de $\mathrm{C}-\mathrm{CO}_{2}$. Para as áreas de SPD e de Cerradão, a natureza mais recalcitrante da MOS (maior relação $\mathrm{C} / \mathrm{N}$ (Tabela 2) e maiores teores da fração F3 (fração moderadamente resistente) na profundidade superficial do solo (LOSS, 2011) acarretam em menor a atividade microbiana (menores picos de C-CO $\mathrm{CO}_{2} \operatorname{logo}$ após a incubação) quando comparado com o sistema de ILP.

No sistema de ILP, independente da classe de agregado avaliada $(8,0-2,0 ; 2,0-1,0 ; 1,0-0,5$; 
0,5-0,25 e 0,25-0,105 mm), Loss et al. (2011) encontraram maiores teores de $\mathrm{C}$ e $\mathrm{N}$ no sistema de ILP quando comparados com a área de SPD. Portanto, no sistema de ILP, os maiores valores de $\mathrm{C}$ e $\mathrm{N}$, assim como de $\mathrm{C}-\mathrm{CO}_{2}$, são decorrentes da conjugação dos fatores rotação de culturas, plantas de cobertura (braquiária) mais dejetos bovinos e do uso das leguminosas soja e feijão em comparação a área de SPD, que utiliza apenas a soja na rotação de culturas (Tabela 1).

Observando-se a dinâmica da evolução do C-CO $\mathrm{CO}_{2}$ no tempo de incubação, aos 7 dias, nos três sistemas avaliados, ocorreu aumento na liberação de $\mathrm{C}-\mathrm{CO}_{2}$, sendo maior na área de Cerradão, seguida das áreas em ILP e SPD e, a partir do $25^{\circ}$ dia ocorreu a estabilização da respiração microbiana (Figura 3). Estes resultados são corroborados por Farias et al. (2005) que avaliando a evolução do C- $\mathrm{CO}_{2}$ de Latossolo Vermelho-Amarelo até 65 dias de incubação observaram que entre o $25^{\circ}$ e $30^{\circ}$ dia ocorreu a estabilização da atividade microbiana.

As maiores liberações de $\mathrm{C}-\mathrm{CO}_{2}$ verificados aos 7 dias (Figura 3) podem ser decorrentes da morte de alguns microorganismos, pois a evolução de $\mathrm{C}-\mathrm{CO}_{2}$ foi gradativamente reduzindo do $4^{\circ}$ até o $6^{\circ}$ dia. Com a morte dos microorganismos possivelmente estes serviram de alimento para os remanescentes (GONÇALVES et al., 2002), originando os maiores valores de liberação de $\mathrm{C}-\mathrm{CO}_{2}$ oriundos da atividade microbiana. Pode-se observar que este padrão se repete ao longo das avaliações, pois do $7^{\circ}$ ao $11^{\circ}$ dia verificou-se diminuição das emissões de $\mathrm{C}-\mathrm{CO}_{2}$, com posterior aumento do $13^{\circ}$ para o $15^{\circ}$ dia, até a estabilização das emissões de $\mathrm{C}-\mathrm{CO}_{2}$ a partir do $25^{\circ}$ dia.

$\mathrm{O}$ maior acúmulo de $\mathrm{C}-\mathrm{CO}_{2}$ (maior atividade microbiana) ocorreu na área de Cerradão e na área de ILP $(0-5 \mathrm{~cm})$. Na profundidade de $5-10 \mathrm{~cm}$, a área de Cerradão apresentou o maior acúmulo de $\mathrm{C}-\mathrm{CO}_{2}$, seguida das áreas em ILP e SPD, respectivamente (Tabela 3). Estes maiores acúmulos de $\mathrm{C}-\mathrm{CO}_{2}$ estão diretamente relacionados ao aporte de material vegetal nas áreas (massa seca de braquiária $=11.300$ $\mathrm{Kg} \mathrm{ha}^{-1}$ ) no sistema de ILP e do milheto $=7.800 \mathrm{Kg}$ $\mathrm{ha}^{-1}$ no SPD) e sua qualidade, sendo que os teores de $\mathrm{C}$ e N presentes na fração leve livre (FLL) da MOS extraída com NaI, na área de Cerradão apresentou valores de 162,66 e 15,08 $\mathrm{g} \mathrm{kg}^{-1}$ em 49,88 $\mathrm{g} \mathrm{kg}^{-1}$ de massa da FLL; no sistema de ILP encontrouse 187,83 e $18,21 \mathrm{~g} \mathrm{~kg}^{-1}$ em $26,17 \mathrm{~g} \mathrm{~kg}^{-1}$ de massa da FLL e, no SPD observaram-se 156,75 e 16,57 em 17,49 $\mathrm{g} \mathrm{kg}^{-1}$ de massa da FLL, ambos nos macroagregados $(8,00-4,00 \mathrm{~mm})$ da camada de 0-10 cm (LOSS et al., 2012b).

Somados aos aportes e qualidade do material vegetal nos sistemas avaliados, tem-se os maiores teores de COT e N nas áreas de Cerradão e de ILP, em comparação aos teores encontrados na área de SPD (Tabela 2). Em relação aos estoques totais de $\mathrm{C}$ e $\mathrm{N}$, verificaram-se maiores valores de $\mathrm{C}$ na área de Cerradão e ILP $(51,45$ e 52,52 Mg ha${ }^{1}$, respectivamente) e menores valores para a área de SPD (44,75 $\left.\mathrm{Mg} \mathrm{ha}^{-1}\right)$ para a camada de 0,0-20,0 $\mathrm{cm}$. Para os estoques de $\mathrm{N}$ nesta camada, a área de Cerradão apresentou os maiores valores, seguida das áreas de ILP e SPD (4,72; 3,11 e 2,76 $\mathrm{Mg} \mathrm{ha}^{-1}$, respectivamente) (LOSS, 2011).

Resultados semelhantes foram observados em estudo sobre o C mineralizável em Latossolo Vermelho em área de plantio direto no Cerrado (GO), onde Rosa et al. (2003) verificaram na área de Cerrado (floresta nativa de Cerradão) os maiores valores de $\mathrm{C}$ mineralizável $\left(\mathrm{C}-\mathrm{CO}_{2}\right)$, sobretudo até $30 \mathrm{~cm}$ de profundidade, tanto para agregados maiores quanto para menores que $250 \mathrm{~mm}$. 
Tabela 3. Acúmulo* de $\mathrm{C}-\mathrm{CO}_{2}\left(\mathrm{mg} \mathrm{CO}_{2} 50 \mathrm{~g}\right.$ de agregados $\left.{ }^{-1}\right)$ durante todo o período de incubação dos agregados do solo nos diferentes sistemas de uso do solo em Montividiu, GO.

\begin{tabular}{lcccc}
\hline \multicolumn{2}{c}{ Camada avaliada } & \multicolumn{4}{c}{ Sistemas de uso do solo } \\
\cline { 2 - 5 }$(\mathbf{c m})$ & $\mathrm{SPD}$ & ILP & Cerradão & CV $(\%)$ \\
\hline $0,0-5,0$ & $78,49 \mathrm{~B}$ & $95,08 \mathrm{~A}$ & $92,87 \mathrm{~A}$ & 12,23 \\
$5,0-10,0$ & $77,55 \mathrm{C}$ & $82,60 \mathrm{~B}$ & $88,83 \mathrm{~A}$ & 11,25 \\
\hline
\end{tabular}

*Médias de quatro repetições. Letras iguais na linha não diferem entre si pelo teste $t-L S D(p<0,05)$. $C V=$ coeficiente de variação. SPD = sistema plantio direto (girassol-milheto-soja-milho); ILP = integração lavoura-pecuária (milho-braquiária-feijão-algodãosoja).

Fonte: Elaboração dos autores.

Através da análise da Tabela 2, verifica-se uma tendência de aumento para os teores de COT (0-5 cm) em relação ao período de incubação, sendo verificado aproximadamente um aumento de 4\% nos teores de COT para as áreas de SPD e ILP após a incubação, e na área de Cerradão foi observado padrão inverso, com valores de COT estatisticamente menores após a incubação (0-5 e 5-10 cm). Para o N, a área de Cerradão apresentou maiores teores após a incubação (0-5 e 5-10 cm) e as áreas em SPD e ILP não diferiram entre as épocas de incubação, com exceção da área de ILP, que apresentou menores teores de $\mathrm{N}$ na profundidade de 0-5 cm, após a incubação.

A tendência do aumento de COT após a incubação nas áreas cultivadas pode ser devido ao ataque dos microorganismos a formas de $\mathrm{C}$ mais estáveis, que estavam protegidas no interior dos macroagregados. Avaliando a evolução de $\mathrm{C}-\mathrm{CO}_{2}$ de solos de várzeas no Sul da China, Zhang, Li e Pan (2006) realizaram o fracionamento isotópico da MOS antes e após a incubação do solo. Os autores observaram que com o aumento do tempo da incubação, os valores de $\delta^{13} \mathrm{C}$ tiveram um enriquecimento isotópico, sendo este padrão atribuído ao ataque de formas de $\mathrm{C}$ mais estáveis pela atividade microbiana. Provavelmente, na área de Cerradão, a maior disponibilidade de material vegetal oriundo da própria vegetação, tais como o conteúdo de matéria orgânica leve e fração leve livre da MOS (LOSS et al., 2012b), que foi incubado juntamente com os agregados, serviu de alimento para os microorganismos, sendo desta forma, verificado um decréscimo dos teores de COT após a incubação.

Os maiores teores de COT e N foram encontrados na área de Cerradão antes e após a incubação, com exceção ao $\mathrm{N}$ antes da incubação, onde a área de ILP não diferiu da área de Cerradão (Tabela 2). Este padrão está relacionado à intensa deposição de resíduos vegetais (serapilheira) e a ausência de influência antrópica nesta área. Dessa forma, temse maiores valores da FLL da MOS, da matéria orgânica leve (MOL) em água e da matéria orgânica particulada (MOP) (LOSS et al., 2012a,b; LOSS, 2011), o que acarretará em maiores teores de COT e $\mathrm{N}$ nos agregados (Tabela 2) e nas classes de agregados (LOSS et al., 2011).

Entre as áreas cultivadas, o sistema de ILP apresentou maiores teores de COT $(0-5 \mathrm{~cm})$ e N (0-10 cm) antes e após a incubação, com exceção da profundidade de $0-5 \mathrm{~cm}$, após a incubação, onde não foram observadas diferenças, em comparação a área de SPD (Tabela 2).

O sistema de ILP, sob intensidades moderadas de pastejo, combina a ausência de revolvimento do solo e o elevado aporte de resíduos vegetais pela utilização de lavouras e pastagens (ANGHINONI et al., 2011; LOSS et al., 2011). Este padrão corrobora os maiores teores de COT e de $\mathrm{N}$ encontrados na área de ILP quando comparados com a área sem pastejo (SPD). Além do efeito benéfico decorrente da rotação de cultura utilizada na área de ILP, que pode acarretar em balanço positivo de N (soja e 
feijão), que por sua vez está atrelado à adição de carbono, permitindo a incorporação conjunta destes elementos à MOS (SISTI et al., 2004; URQUIAGA et al., 2005; JANTALIA et al., 2007).

Portanto, o sistema de ILP está sendo mais eficiente em aumentar os teores de COT e $\mathrm{N}$ nos macroagregados do solo (Tabela 2 ) e nas diferentes classes de agregados $(8,0-2,0 ; 2,0-1,0 ; 1,0-0,5 ; 0,5-$ 0,25 e $0,25-0,105 \mathrm{~mm}$, Loss et al. (2011)) quando comparado com o SPD. E, esses maiores teores de $\mathrm{C}$ e N estão favorecendo a agregação do solo nesta área, culminando em agregados mais estáveis em água, e consequentemente, menores valores de densidade do solo (LOSS et al., 2011). Segundo esses autores, no sistema de ILP foram encontrados maiores teores de COT nos agregados de 8,0-2,0 mm (36,92 $\left.\mathrm{g} \mathrm{kg}^{-1}\right) ; 2,0-1,0 \mathrm{~mm}\left(31,87 \mathrm{~g} \mathrm{~kg}^{-1}\right) ; 1,0-$ $0,5 \mathrm{~mm}\left(31,60 \mathrm{~g} \mathrm{~kg}^{-1}\right) ; 0,5-0,25 \mathrm{~mm}\left(28,86 \mathrm{~g} \mathrm{~kg}^{-1}\right)$ e $0,25-0,105 \mathrm{~mm}\left(28,06 \mathrm{~g} \mathrm{~kg}^{-1}\right)$ quando comparado com o SPD $\left(30,30 ; 26,49 ; 23,83 ; 22,61\right.$ e $23,62 \mathrm{~g} \mathrm{~kg}^{-}$ ${ }^{1}$, respectivamente para $8,0-2,0 ; 2,0-1,0 ; 1,0-0,5$; $0,5-0,25$ e $0,25-0,105 \mathrm{~mm})$.

Os menores valores da relação $\mathrm{C} / \mathrm{N}$ foram encontrados na área de ILP, antes da incubação, e na área de Cerradão, após a incubação (Tabela 3). $\mathrm{Na}$ área de ILP, os menores valores são decorrentes do uso de duas leguminosas na rotação de culturas e dos maiores teores de frações mais lábeis da MOS (FLL, MOL e MOP) (LOSS, 2011; LOSS et al. 2012b). Na área de Cerradão, os menores valores estão relacionados à diminuição dos teores de COT e ao aumento dos teores de $\mathrm{N}$, ambos após a incubação.

De forma geral, as maiores liberações (Figura 3) e acúmulos de $\mathrm{C}-\mathrm{CO}_{2}$ (Tabela 3) associados aos maiores teores de COT e N (Tabela 2) verificados no sistema de ILP quando comparado ao SPD, permitem inferir que há maior quantidade de carbono potencialmente mineralizável no sistema de ILP. E, o maior acúmulo $\mathrm{C}-\mathrm{CO}_{2}$ no sistema de ILP irá acarretar maior ciclagem de carbono e nutrientes para as culturas comerciais implantadas
(D‘ANDRÉA et al., 2002). Essas diferenças estão diretamente relacionadas com a intensa ciclagem de raízes no sistema de ILP, devido ao conjunto de fatores que esse sistema engloba, tais como a rotação de culturas, plantas de cobertura, pastejo bovino (associado aos dejetos bovinos deixados na superfície do solo) em comparação ao SPD.

\section{Conclusões}

O sistema de integração lavoura-pecuária (ILP) acarreta em maiores liberações e acúmulos de $\mathrm{C}-\mathrm{CO}_{2}$ quando comparado com a área de sistema plantio direto (SPD), culminando em maior quantidade de carbono potencialmente mineralizável na área de ILP.

A integração dos fatores rotação de culturas, plantas de cobertura e pastejo bovino no sistema de ILP aumenta os teores de carbono e nitrogênio nos macroagregados do solo em comparação a área de SPD.

\section{Agradecimentos}

À Fundação Agrisus pelo custeio do projeto de pesquisa, ao CNPq e a FAPERJ pela concessão de bolsa de Doutorado ao primeiro autor, ao Curso de Pós-Graduação em Agronomia - Ciência do Solo (CPGA-CS) pelo auxílio prestado e ao Dr. Adriano Perin e colaboradores pelo auxílio na coleta das amostras de solo para a realização deste estudo.

\section{Referências}

ANGHINONI, I.; MORAES, A.; CARVALHO, P. C. F.; SOUZA, E. D.; CONTE, O.; LANG, C. R. Benefícios da integração lavoura-pecuária sobre a fertilidade do solo em sistema plantio direto. In: FONSECA, A. F.; CAIRES, E. F.; BARTH, G. Fertilidade do solo e nutrição de plantas no sistema plantio direto. Ponta Grosa: AEACG/Inpag, 2011. p. 1-31.

ASSIS JÚNIOR, S. L.; KAZUYA, M. C. M.; COUTO, L. Atividade microbiana do solo em sistemas agroflorestais, monoculturas, mata natural e área desmatada. Revista Árvore, Viçosa, v. 27, n. 1, p. 35-41, 2003. 
BALDOCK, J. A.; OADES, J. M.; WATERS, A. G.; PENG, X.; VASSALLO, A. M.; WILSON, M. A. Aspects of the chemical structure of soil organic materials as revealed by solid-state ${ }^{13} \mathrm{C}$ NMR spectroscopy. Biogeochemistry, Dordrecht, v. 16, n. 1, p. 1-42, 1992.

BODDEY, R.; JANTALIA, C. P.; CONCEIÇÃO, P. C. E.; ZANATTA, J. A.; MIELNICZUK, J.; DIECKOW, J.; SANTOS, H. P.; DENARDIN, J. E.; GIACOMINI, S. J.; URQUIAGA, S. C. S.; ALVES, B. J. R. Carbon accumulation at depth in Ferralsols under zero-till subtropical agriculture. Global Change Biology, Urbana, v. 16, n. 2, p. 784-795, 2010.

BOSSUYT, H.; SIX, J.; HENDRIX, P. F. Aggregateprotected carbon in no-tillage and conventional tillage agroecosystems using carbon-14 labeled plant residue. Soil Science Society of American Journal, Madison, v. 66, n. 6, p. 1965-1973, 2002.

BROOKES, P. C. The use of microbial parameters in monitoring soil pollution by heavy metals. Biology and Fertility of Soils, Germany, v. 19, n. 4, p. 269-279, 1995.

CARVAlHo, J. L. N. Dinâmica d carbono e fluxo de gases do efeito estufa em sistemas de integração lavoura pecuária na Amazônia e no Cerrado. 2009. Tese (Doutorado em Solos e Nutrição de Plantas) - Escola Superior de Agricultura Luiz de Queiroz, Piracicaba.

CARVALHO, J. L. N.; RAUCCI, G. S.; CERRI, C. E. P.; BERNOUX, M.; FEIGL, B. J.; WRUCK, F. J.; CERRI, C. C. Impact of pasture, agriculture and crop-livestock systems on soil $\mathrm{C}$ stocks in Brazil. Soil and Tillage Research, Amsterdam, v. 110, n. 1, p. 175-186, 2010.

CARVALHO, P. C. F. Integração lavoura-pecuária em sistema de plantio direto. 2007. Disponível em: <http:// www.agroredenoticias.com.br/textos.aspxhttp://www. agroredenoticias.com.br/textos.aspx $>$. Acesso em: 22 jun. 2010.

CRUSCIOL, C. A. C.; BORGHI, E. Consórcio de milho com braquiária: produção de forragem e palhada para o plantio direto. Revista Plantio Direto, Passo Fundo, ed. 100, p. 6, 2007.

D‘ANDRÉA, A. F.; SILVA, M. L. N.; CURI, N.; SIQUEIRA, J. O.; CARNEIRO, M. A. C. Atributos biológicos indicadores da qualidade do solo em sistemas de manejo na região do Cerrado no sul do estado de Goiás. Revista Brasileira de Ciência do Solo, Viçosa, MG, v. 26, n. 4, p. 913-923, 2002.

DAVIDSON, E. A.; BELK, E.; BOONE, R. D. Soil water content and temperature as independent or confounded factors controlling soil respiration in a temperate mixed hardwood forest. Global Change Biology, Urbana, v. 4, p. 217-227, 1998.
EMPRESA BRASILEIRA DE PESQUISA AGROPECUÁRIA - EMBRAPA. Manual de métodos de análise de solo. 2. ed. Rio de Janeiro: CNPS, 1997.

Sistema brasileiro de classificação de solos. 2. ed. Brasília: Embrapa Produção de informação; Rio de Janeiro: Embrapa Solos, 2006. 312p.

Integração lavoura, pecuária e floresta. 2009. Disponível em: <www.cnpc.org.br/arquivos/ integlavpecflo.pdf.>. Acesso em: 22 jun. 2010.

FARIAS, E. P.; ZONTA, E.; SANTOS, G.; ASANTOS, G. A.; CANELLAS, L.; PCANELLAS, L. P. Aporte de carbono solúvel pelo sistema radicular de arroz e sua influência nos teores de substâncias húmicas de um Latossolo Vermelho-Amarelo. Revista Brasileira de Ciência do Solo, Viçosa, MG, v. 29, n. 6, p. 875-882, 2005.

FERREIRA, E. V. O.; ANGHINONI, I.; ANDRIGHETTI, M. H.; MARTINS, A. P.; CARVALHO, P. C. F. Ciclagem e balanço de potássio e produtividade de soja na integração lavoura-pecuária sob semeadura direta. Revista Brasileira de Ciência do Solo, Viçosa, MG, v. 35, n. 1, p. 161-169, 2011.

FONTANA, A.; LOSS, A.; PEREIRA, M. G.; CUNHA, T. J. F.; SALTON, J. C. Atributos de fertilidade e frações húmicas de um Latossolo Vermelho no Cerrado. Pesquisa Agropecuária Brasileira, Brasília, v. 41, n. 6, p. 847-853, 2006.

FRANCHINI, J. C.; DEBIASI, H.; WRUCK, F. J.; SKORUPA, L. A.; WINK, N. N.; GUISOLPHI, I. J.; CAUMO, A. L.; HATORI, T. Integração lavourapecuária: alternativa para diversificação e redução do impacto ambiental do sistema produtivo no Vale do Rio Xingu. Londrina: Embrapa Soja, 2010. 20 p. (Circular técnica, 77).

GONÇALVES, A. S.; MONTEIRO, M. T.; GUERRA, J. G. M.; DE-POLLI, H. Biomassa microbiana em amostras de solos secadas ao ar e reumedecidas. Pesquisa Agropecuária Brasileira, Brasília, v. 37, n. 5, p. 651-658, 2002.

JANTALIA, C. P.; RESCK, D. V. S.; ALVES, B. J. R.; ZOTARELLI, L.; URQUIAGA, S.; BODDEY, R. M. Tillage effect on $\mathrm{C}$ stocks of a clayey oxisol under a soybean-based crop rotation in the Brazilian Cerrado. Soil and Tillage Research, Amsterdam, v. 95, n. 1-2, p. 97-109, 2007.

KENNEDY, A. C.; SMITH, K. L. Soil microbial diversity and the sustainability of agricultural soils. Plant Soil, The Hague, v. 170, n. 1, p. 75-86, 1995. 
KUZYAKOV, Y.; FRIDEL, J. K.; STAHR, K. Review of mechanisms and quantification of priming effects. Soil Biology and Biochemistry, Oxford, v. 32, n. 11-12, p. 1485-1498, 2000.

LEITE, L. F. C.; GALVÃO, S. R. S.; HOLANDA NETO, M. R.; ARAÚJO, F. S.; IWATA, B. F. Atributos químicos e estoques de carbono em Latossolo sob plantio direto no cerrado do Piaú. Revista Brasileira de Engenharia Agricola e Ambiental, v. 14, n. 12, p. 1273-1280, 2010.

LIEBIG, M. A.; TANAKA, D. L.; KRONBERG, S. L.; SCHOLLJEGERDES, E. J.; KARN, J. F. Integrated crops and livestock in central North Dakota, USA: Agroecosystem management to buffer soil change. Renewable Agriculture and Food Systems, Cambridge, v. 27, n. 2, p. 115-124, 2012.

LOSS, A. Dinâmica da matéria orgânica, fertilidade e agregação do solo em áreas sob diferentes sistemas de uso no Cerrado goiano. 2011. Tese (Doutorado em Agronomia - Ciência do Solo) - Universidade Federal Rural do Rio de Janeiro, Seropédica.

LOSS, A.; PEREIRA, M. G.; ANJOS, L. H. C.; GIACOMO, S. G.; PERIN, A. Agregação, carbono e nitrogênio em agregados do solo sob plantio direto com integração lavoura-pecuária. Pesquisa Agropecuária Brasileira, Brasília, v. 46, n. 10, p. 1269-1276, 2011.

LOSS, A.; PEREIRA, M. G.; PERIN, A.; ANJOS, L. H. C. Carbon and nitrogen content and stock in no-tillage and crop-livestock integration systems in the Cerrado of Goias State, Brazil. Journal of Agricultural Science, Cambridge, v. 4, n. 8, p. 96-105, 2012a.

LOSS, A.; PEREIRA, M. G.; PERIN, A.; BEUTLER, S. J.; ANJOS, L. H. C. Carbon, nitrogen and natural abundance of ${ }^{13} \mathrm{C}$ e ${ }^{15} \mathrm{~N}$ of light-fraction organic matter under no-tillage system and crop-livestock integration in the Cerrado. Acta Scientiarum. Agronomy, Maringá, v. 34, n. 4, p. 468-474. 2012 b.

LOSS, A.; PEREIRA, M. G.; SCHULTZ, N.; ANJOS, L. H. C.; SILVA, E. M. R. Quantificação do carbono das substâncias húmicas em diferentes sistemas de uso do solo e épocas de avaliação. Bragantia, Campinas, v. 69, n. 4, p. 913-922, 2010.

MACEDO, M. C. M. Integração lavoura e pecuária: o estado da arte e inovações tecnológicas. Revista Brasileira de Zootecnia, Viçosa, MG, v. 38, p. 133-146, 2009. Especial.

MACHADO, P. L. A. O. Carbono do solo e a mitigação da mudança climática global. Química Nova, São Paulo, v. 28 , n. 2, p. 329-334, 2005.
MIELNICZUK, J.; BAYER, C.; VEZZANI, F.; LOVATO, T.; FERNANDES, F. F.; DEBARBA, L. Manejo de solo e culturas e sua relação com estoques de carbono e nitrogênio do solo. In: CURI, N.; MARQUES, J. J.; GUILHERME, L. R. G.; LIMA, J. M.; LOPES, A. S. S.; ALVAREZ V., V. H. (Ed.). Tópicos em ciência do solo. Viçosa, MG, Sociedade Brasileira de Ciência do Solo, 2003. v. 3, p. 209-248.

MENDONÇA, E. S.; MATOS, E. S. Matéria orgânica do solo: métodos de análises. Ponte Nova: D \& M Gráfica e Editora Ltda, 2005. 107 p.

ROSA, M. E. C.; OLSZEVSKI, N.; MENDONÇA, E. S.; COSTA, L. M.; CORREIA, J. R. Formas de carbono em Latossolo Vermelho Eutroférrico sob plantio direto no sistema biogeográfico do Cerrado. Revista Brasileira de Ciência do Solo, Viçosa, MG, v. 27, n. 5, p. 911-923, 2003.

ROSSI, C. Q.; PEREIRA, M. G.; GIÁCOMO, S. G.; BETTA, M.; POLIDORO, J. C. Frações lábeis da matéria orgânica em sistema de cultivo com palha de braquiária e sorgo. Revista Ciência Agronômica, Fortaleza, v. 43, n. 1, p. 38-46, 2012.

SILVA, R. F.; GUIMARÃES, M. F.; AQUINO, A. M.; MERCANTE, F. M. Análise conjunta de atributos físicos e biológicos do solo sob sistema de integração lavourapecuária. Pesquisa Agropecuária Brasileira, v. 46, n. 10, p. 1277-1283, 2011.

SIQUEIRA NETO, M. Estoques de carbono e nitrogênio do solo com diferentes usos no Cerrado em Rio Verde, GO. 2006. Tese (Doutorado em Agricultura) - PósGraduação no Centro Nuclear de Energia na Agricultura. Universidade de São Paulo, Piracicaba.

SIQUEIRA, J. O.; MOREIRA, F. M. S.; GRISI, B. M.; HUNGRIA, M.; ARAÚJO, R. S. Microrganismos e processos biológicos do solo: perspectiva ambiental. Brasília: Embrapa, 1994. 142 p.

SISTI, C. P. J.; SANTOS, H. P.; KOHHANN, R.; ALVES, B. J. R.; URQUIAGA, S.; BODDEY, R. M. Change in carbon and nitrogen stocks in soil under 13 years of conventional or zero tillage in southern Brazil. Soil and Tillage Research, Amsterdam, v. 76, n. 1, p. 39-58, 2004.

SOUZA, E. D.; COSTA, S. E. V. G. A.; ANGHINONI, I.; CARVALHO, P. C. F.; ANDRIGUETI, M.; CAO, E. Estoque de carbono orgânico e de nitrogênio no solo em sistema de integração lavoura-pecuária em plantio direto, submetidos a intensidades de pastejo. Revista Brasileira de Ciência do Solo, Viçosa, MG, v. 33, n. 6, p. 18291836, 2009. 
SOUZA, E. D.; COSTA, S. E. V. G. A.; ANGHINONI, I.; LIMA, C. V. S.; CARVALHO, P. C. F.; MARTINS, A. P. Biomassa microbiana do solo em sistema de integração lavoura-pecuária em plantio direto, submetido a intensidades de pastejo. Revista Brasileira de Ciência do Solo, Viçosa, MG, v. 34, n. 1, p. 79-88, 2010.

TEDESCO, M. J.; VOLKWEISS, S. J.; BOHNEN, H. Análise de solo, plantas e outros materiais. Porto Alegre: Universidade Federal do Rio Grande do Sul, 1995. 188 p.

TEIXEIRA, L.; LA SCALA JÚNIOR, N.; LOPES, A. Fluxo de $\mathrm{CO}_{2}$ do solo após aração e escarificação em diferentes condições. Holos Environment, Rio Claro, v. 10, n. 1, p. 1-11, 2010.

TRACY, B. F.; ZHANG, Y. Soil compaction, corn yield response and soil nutrient pool dynamics within an integrated crop-livestock system in Illinois. Crop Science, v. 48, n. 3, p. 1211-1218, 2008.

URQUIAGA, S.; JANTALIA, C. P.; ZOTARELLI, L.; ALVES, B. J. R.; BODDEY, R. M. Manejo de sistemas agrícolas para o seqüestro de carbono no solo. In: AQUINO, A. M.; ASSIS, R. L. (Org.). Conhecimentos e técnicas avançadas para o estudo dos processos da biota no sistema solo-planta. Brasília: Embrapa, 2005. p. 257273.
VILELA, L.; MARTHA JUNIOR, G. B.; MACEDO, M. C. M.; MARCHÃO, R. L.; GUIMARÃES JÚNIOR, R.; PULROLNIK, K.; MACIEL, G. A. Sistemas de integração lavoura-pecuária na região do Cerrado. Pesquisa Agropecuária Brasileira, Brasília, v. 46, n. 10, p. 1127-1138, 2011.

YEOMANS, J. C.; BREMNER, J. M. A rapid and precise method for routine determination of organic carbon in soil. Communication Soil Science And Plant Analysis, Philadelphia, v. 19, n. 13, p. 1467-1476, 1988.

ZHANG, X. H.; LI, L. G.; PAN, G. X. Topsoil organic carbon mineralization and $\mathrm{CO} 2$ evolution of three paddy soils from South China and the temperature dependence. Journal of Environmental Sciences, Beijing, v. 19, n. 3, p. 319-326, 2006.

ZIBILSKE, L. M. Carbon mineralization. In: WEAVER, R.W.; ANGLE, S.; BOTTOMLEY, P.; BEZDICEK, D.; SMITH, S.; TABATABAI, A.; WOLLUM, A. Methods of soil analysis. Part 2. Microbiological and biochemical properties. Madison: Soil Science Society of America, 1994. p. 835-863. (Book Series, 5). 
